\title{
Research on the Design Ideas of Exhibition Design from the Perspective of Visual Beauty
}

\author{
Wang Qian \\ Academy of Arts, Xi'an Fanyi University, 710105
}

Keywords: Visual Beauty; Aesthetic Consciousness; Design Ideas; Functionality

\begin{abstract}
Exhibition design is typically nested in various fields, such as all kinds of museums, shopping malls and window display stands, etc. Besides, exhibition design covers different contents at many levels, including the planning and development of exhibits, the application of various spaces, etc. In other words, the design idea of exhibition design shall take into account the issue that how a variety of exhibition factors can fully reveal the characteristics of goods and the advantages of enterprises within certain time and space so as to achieve economic benefits or commercial interests. However, the diversiform development of modern society has impelled people to improve their spiritual needs and psychological demands for aesthetics and cultures during the process of consumption. The exhibition design therefore, tends to take the aesthetic experiences and aesthetic knowledge as the design idea and develop an integrated system design that combines functionality with aesthetics by creating certain degrees of visual beauty. This paper is composed of three parts: Firstly, give a short introduction on the development and dissemination of exhibition design; secondly, describe the influence of visual beauty on the design ideas of exhibition design; lastly, use examples to analyze the formal expression of exhibition design from the perspective of visual beauty. In short, the preference of exhibition design for visual beauty can not only promote the development of exhibition design, but is conducive to stimulating market economy and enhancing the aesthetic consciousness of the public.
\end{abstract}

\section{Introduction}

Exhibition design, as an artistic design with comprehensive nature, has gradually developed with the development of human society, economy and politics. Exhibition design has blended into many industries and derived abundant design languages. According to the commerciality of exhibition design, exhibition design requires the designers to use pluralistic art design languages to elaborately design and arrange the three-dimensional spaces or two-dimensional planes within the vested time and space so that the three-dimensional spaces or two-dimensional planes can break through the solidified spatial structure and establish a rational relation with the exhibits, which not only plays a helping role in the publicity of exhibits, but improves the viewers' sense of participation and achieves the communication purpose properly.

From the perspective of design scope, the aesthetic-creating practices of exhibition design shall be developed on the basis of and complemented by primary needs of human beings so as to promote a virtuous cycle of development. This is why the contemporary exhibition design is very keen on visual beauty. The exhibition design, as a kind of design within the design field, is inseparable from aesthetics. In addition, people generate constantly improving spiritual needs and become rigorous about the aesthetic perception after the satisfaction of material needs. Thus, the design ideas of exhibition design are increasingly correlated to the visual beauty.

\section{Development and dissemination of exhibition design}

From one point of view, exhibition design is an emerging industry among various industries and has a quite broad concept, such as the architectural design with certain scale and stability, the interior space design that focuses on spatial arrangement, or some temporary exhibition designs (such as arts and crafts). 
Expositions sprang up at the end of the $19^{\text {th }}$ century and the beginning of $20^{\text {th }}$ century. The "shopping malls" or "stores" began to scale up and became more specialized and systematic after World War II, which laid a solid foundation for the development of exhibition design.

Nowadays, considering that the aesthetic consciousness of viewers has improved significantly and the exhibition design has made great progresses after integrating the superiorities of many fields, the exhibition design thus, is no longer provided with such a simple concept. Certainly, the rapid development of exhibition design benefits from the progresses of other fields, such as the construction industry. In addition, the design ideas of exhibition design are ever-changing due to the impacts of emerging arts. The ideas of modern exhibition design are mainly reflected in humanization and subjectification. In recent years, the psychological cognition of visitors has been analyzed and interpreted by sociologists and psychologists from different points of views. The application of these findings in the exhibition design is extremely obvious. The coalescence of science and technology is the primary approach to achieve both material display and spiritual communication of exhibition design in the information era. The psychological and physiological demands of viewers shall be met as far as possible so as to acquire benefit and efficiency.

\section{The influence of visual beauty on the design ideas of exhibition design}

In short, visual beauty, as a relatively broad concept, is the sense of joviality visually generated by one thing. The effect of visual beauty cannot be achieved without the coordination of many factors. The application of shapes, colors and materials may pose impacts on people's feeling about visual beauty. It is a complex problem that what kind of works or elements combination can achieve ideal visual beauty. A complete system shall be developed sometimes. Visual communication is nothing but a science.

Modern exhibition design appears more relaxing and enjoyable when compared with that in the past, which benefits from the fact that the designers are capable of combining the freedom of art with exquisite technologies in a proper way and expand the boundary of exhibition design from a cognitive perspective. Such idea has rooted in all walks of life, including some purely commercial fields, so does commercial exhibition, which laterally reflects the changes in aesthetic standards of viewers. Thus, the designers shall not only be proficient at various design tactics and implementation techniques, but be required to possess artistic accomplishments, to get hold of the market disciplines, as well as to properly mix all elements together. Only in this way, can the design works give expression to the features of the exhibition and generate certain degrees of visual beauty, which, in turn, meets the psychological needs of customers whose aesthetic standards is enhanced constantly.

The influence of visual beauty on the design ideas of exhibition design is mainly embodied at the following aspects:

\subsection{Improve the diversity of materials}

In general, the traditional exhibition design always takes into account the exhibition of exhibits in a simple and direct manner so as to achieve the economic benefits or other purposes. In view of the cognitions of most customers to be improved and the shortage of materials, the presentation styles of traditional exhibition design are quite boring and unitary. The final exhibition is short of certain visual beauty, which leads the designers to be hard to give full play to their ideas and innovations. In order to improve the visual beauty of design works, it is of great necessity to "play hard" with respect to the materials so that the innovative ideas and design thoughts cannot be impaired due to the limitations of materials, which to a large extent, will promote the generation and application of new materials and technologies, improve the reduction degree of designing schemes and shorten the effort and time consumed during the implementing process.

\subsection{Promote the infiltration of art into public aesthetics consciousness}

There is a relationship of action and retroaction between exhibition design and public aesthetics consciousness. With the development of economy, people may improve their aesthetics 
consciousness and become more meticulous about the pursuit of beauty, while the designers, as a social group that possesses higher degree of artistic accomplishment and gets hold of much aesthetic knowledge, is responsible for spreading the aesthetic concepts by virtue of the design works. The art may improve the aesthetic appreciation of people while gradually penetrating into public aesthetics consciousness via the channels of exhibition. The mutual promotion and virtuous circle produce positive impacts on art and public aesthetics consciousness.

\subsection{Promote the vitality of design field}

The exhibition design covers the forms of planes and the segmentation and combination of spaces. The pursuit of visual beauty has driven the exhibition design to develop in the comprehensive and general direction. For this reason, it is of great necessity to introduce other professions, which can not only enrich the creative language of exhibition design, but greatly fortify the vitality of design field.

\subsection{Promote the exchange between exhibits and viewers}

The affinity between goods and consumers is based on the capability of exhibition to restore the authenticity and reliability of exhibits, which requires the exhibition designers to take into account the coordination of exhibits and exhibition spaces during the process of actual design so as to fully reflect the advantages and characteristics of exhibits, to shorten the distance between exhibits and viewers and generate sense of closeness. Therefore, the pursuit of visual beauty in the process of design, to a large extent, can shorten the distance between exhibits and viewers. This is because we are all visual creatures and may produce general feelings about the visual beauty. When the environmental atmosphere of exhibition space produces sense of beauty and attractions, the consumers may be more active to learn about the product performance and enhance their trust and goodwill of the brand and the enterprise. Only in this way can the consumers take positive attitudes and accept the publicity information with ease.

\section{Contents and forms of exhibition design from the perspective of visual beauty}

People's demands for visual beauty originate from the needs to cast off common customs. Therefore, modern designers shall not only possess sound artistic accomplishments and specialized knowledge, but learn to extend the design ideas by utilizing modern scientific and technological means. The forms of exhibition design may refer to the architectural art, plastic art, environmental art and painting art that are closely related to exhibition design. For exhibition design, the designers shall take the overall layout as an entry point and perform creative conception and design in accordance with the inherent conditions of space, the core topics of display content and technical skills or other conditions so as to achieve the visual beauty. Therefore, the level of exhibition shall be designed properly and produce sense of beauty based on the performance of exhibits.

The composition of space is the foundation for the establishment of visual beauty. For example, the interface design within the indoor exhibition space shall integrate the complicacy with simplicity; for the function division of space, the sales area shall be combined with the leisure area so that consumers can relax a little bit after the fatigue shopping. Consumers can obtain the humanized warmth in the leisure area that is provided by the merchant and get a positive shopping experience.

Color is also a primary factor of exhibition design, including the overall tone and local color relationship. When design the colors of an exhibition, the designers shall pay attention to the overall and local relationships of colors so that the local color cannot supersede or be covered by the overall tone, while the overall tone can provide the viewers with rich visual perceptions and motivate their interests. The exhibition designer shall take into account the color assortment between walls and floors within the exhibition area, the indoor lighting design, as well as the visual experiences, artistic atmospheres and psychological feelings that such color assortment can generate.

The rapid development of contemporary science and technology has greatly changed the artistic 
design in terms of concept and forms, and the exhibition design is no exception. With the advancement of science and technology across the world and the constantly upgrading types of art, the effect of exhibition has experienced a growing improvement. The artistic form based on science and technology allows the exhibition design to develop in a diversified and comprehensive way and also provides people with new visual beauty and interactive feelings.

What's more, material is a major factor of exhibition design from the perspective of visual beauty. Materials can determine people's psychological feelings about the tactile sense and consumer's positioning of quality. For example, the exhibition design of clothing may focus on the proper selection of weak-quality and strong-quality materials, including the visual effects of materials and the fashion degrees and trends of new materials. Proper material layout will fortify the depth and volume perceptions of space and make up the deficiencies of space.

\section{Conclusion}

The exhibition design has involved many areas of specialization. It possesses stronger market operability when compared with other design types. Due to the market demands, people pose higher requirements for the visual beauty of exhibition design, and the exhibition design therefore, is developing at various levels and complementary with public aesthetic consciousness, which has greatly stimulated the design field. The design ideas of exhibition design from the perspective of visual beauty cannot be performed without rich aesthetic knowledge, ever-changing market demands and the professional and artistic accomplishments of the designers. Only in this way can we produce more innovative and humanized design works. In addition, with the constant development and innovation of technology in the new era, our life is reshaped by technologies. People have appreciated the profound influences of computer technology, communication technology, network technology and multimedia technology. With the help of advanced technologies and approaches, designers have opportunities to expand horizons and alter their thinking methods. Therefore, the designers shall pay attention to the application of various information-based means and make innovations in terms of design concept, design language, design method, pattern of expression and appeal so as to promote the development and reform of design works.

\section{References}

[1] Guo Hao and Wang Qiangui. Exhibition Design and Practice. Shanghai Jiao Tong University Press. 2005.

[2] Ren Zhangquan. Exhibition Design. Jiangsu Fine Art Press. 2002.

[3] Zhang Jianfeng and Zhou Ren. Art Works of Display Design. Xuelin Publishing House, 2004.

[4] Wang Xiaosheng and Jiang Zhibin. Modern Advertising Design. Fudan University Press. 2005.

[5] Wang Liying. Study on Shape Generation and Spatial Characteristics in Bionic-structure Architecture [D]. Chongqing: Chongqing University, 2008.

[6] Zhang Junzhu. The Research of Bionic Design Methods Application in the Display Design[J]. Design, 2013, (6): 139-141.

[7] Du Chen. The Application of Ice Crack in Modern Architectural Ornament [J]. Journal of Donghua University (Social Science), 2011, (3): 218-22

[8] Quan Wei. Research on Augmented Reality-based Interactive Spatial Art Composition and Aesthetic Experience. Master Dissertation of Harbin Institute of Technology, 2011.

[9] Yan Shengxue. The Cross-sectional Study of Space-Information space-exhibition design. Master Dissertation of Wuhan University of Technology, 2003.

[10] Xuan Hongbo and Zhang Shiyu. Spatial Art in Display Design. Journal of Inner Mongolia 
Nationality University, 2010(1)

[11] Gu Lei. Spatial Design in Urban Areas Makes Life Better---A Case Study of Xi'an. MASTER, 2011(5)

[12] Wei Xingchen. An Analysis of Visual Communication and Multimedia Design. China Science and Technology Review, 2010.

[13] Ge Zhong. Multimedia Design and Visual Communication. Examination Week, 2007.23.

[14] Gao Peng. The Relationship between Visual Symbol Design and Modern Communication Media: A Case Study of One Greeting Card. Modern Communication, 2010. 